\title{
Thermal Characterization of a Direct Gain Solar Thermal Engine
}

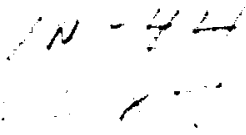

by

\author{
Reginald A. Alexander \\ Structures and Thermal Analysis Branch \\ Preliminary Design Division \\ NASA Marshall Space Flight Center \\ Huntsville, AL \\ and \\ Hugh W. Coleman \\ Propulsion Research Center \\ Department of Mechanical and Aerospace Engineering \\ University of Alabama in Huntsville \\ Huntsville, AL
}

submitted for presentation at the conference on

Renewable and Advanced Energy Systems for the $21^{\text {st }}$ Century

Maui, Hawaii

April 11-15, 1999

September 1998 


\begin{abstract}
A thermal/fluids analysis of a direct gain solar thermal upper stage engine is presented and the results are discussed. The engine has been designed and constructed at the NASA Marshall Space Flight Center for ground testing in a facility that can provide about 10 kilowatts of concentrated solar energy to the engine. The engine transfers that energy to a coolant (hydrogen) that is heated and accelerated through a nozzle to produce thrust. For the nominal design values and a hydrogen flowrate of $2 \mathrm{lb} / \mathrm{hr}$, the results of the analysis show that the hydrogen temperature in the chamber (nozzle entrance) reaches about $3800^{\circ} \mathrm{F}$ after 30 minutes of heating and about $3850^{\circ} \mathrm{F}$ at steady-state (slightly below the desired design temperature of about $4100^{\circ} \mathrm{F}$ ). Sensitivity analyses showed these results to be relatively insensitive to the values used for the absorber surface infrared emissivity and the convection coefficient within the cooling ducts but very sensitive to the hydrogen flowrate. Decreasing the hydrogen flowrate to $\mathrm{l} \mathrm{lb} / \mathrm{hr}$. increases the hydrogen steady-state chamber temperature to about $4700^{\circ} \mathrm{F}$, but also causes an undesirable decrease in thrust.
\end{abstract}




\section{BACKGROUND}

In NASA's efforts to find better and cheaper ways to explore space and get payloads into Earth orbit, engineers have investigated means of producing thrust other than by chemical propulsion. One of these innovative approaches is using solar energy to produce thrust. A solar thermal engine collects concentrated solar energy which is used to heat a propellant to temperatures on the order of $4000^{\circ} \mathrm{F}$ to $5000^{\circ} \mathrm{F}$. The heated propellant exits at a high velocity through the engine's nozzle, thus producing thrust. There are technology limitations to these concepts though. Absorber materials such as tungsten, henium or molybdenum that will be able to withstand these high temperatures are required. Also, flexible concentrators large enough to focus enough energy into the absorber with accurate pointing and stiffness along with being lightweight will be a considerable technical challenge.

In November of 1993 NASA Headquarters asked the Marshall Space Flight Center (MSFC) to perform an assessment of a Solar Thermal Upper Stage (STUS) concept proposed by the Hercules Aerospace Company. The conclusions of this assessment were that there were no technical issues that would render the project infeasible. The engineers performing the assessment recommended that the Preliminary Design Office (PD) of MSFC conduct a Preliminary Design Study[1] of the STUS to determine its technical and economic feasibility. This upper stage would be designed to deliver a $1000 \mathrm{lbm}$ payload to geo-synchronous orbit. The design uses two parabolic solar reflectors to focus sunlight into a black body cavity made of a high temperature material. The overall concentration factor for the collector/reflector is $4356: 1$. The energy is used to achieve a predicted specific impulse $\left(I_{\mathrm{sp}}\right)$ of $860 \mathrm{sec}$. at a propellant temperature of $4112^{\circ} \mathrm{F}$ and an engine thrust of $2 \mathrm{lbf}$.

The performance of rockets is measured by thrust produced and specific impulse $\left(I_{\mathrm{sp}}\right)$ which is the ratio of the thrust to propellant flow rate. The major benefit to using the solar thermal engine is the expected increased specific impulse. This high $I_{\mathfrak{p p}}$ is due to the low molecular weight of $\mathrm{H}_{2}$ and the exhaust velocities of the propellant exiting the nozzle. Compressible flow 
equations show that the $\mathrm{I}_{\mathrm{sp}}$ of a given nozzle is proportional to $\sqrt{T_{c} / M}$, where $\mathrm{T}_{\mathrm{c}}$ is the propellant stagnation temperature and $M$ is the propellant molecular weight[2]. Increasing the propellant temperature or decreasing its molecular weight increases the $\mathrm{I}_{3 \mathrm{p}}$. Since $\mathrm{H}_{2}$ has the lowest molecular weight of any element, increasing the temperature is necessary to increase the $I_{s p}$. Typical $\mathrm{LO}_{2} / \mathrm{LH}_{2}$ chemical stages have $\mathrm{I}_{\mathrm{sp}}$ of $436 \mathrm{sec}$. whereas the STUS should have an $\mathrm{I}_{\mathrm{sp}}$ of $860 \mathrm{sec}$. provided a fluid temperature of approximately $4112^{\circ} \mathrm{F}$ can be attained. The stage, though, will probably only produce about $2 \mathrm{lb}$. of thrust, which only makes it useful to boost payloads to higher orbits over a long period of time.

Also in conjunction with the PD activities, in 1995 engineers at MSFC began work on a Center Director's Discretionary Fund (CDDF) Project[3] to build and test a solar thermal engine. This engine would use hydrogen $\left(\mathrm{H}_{2}\right)$ as its propellant. The work presented here focuses on the thermal/fluids modeling of the engine for the NASA CDDF Project. The models developed were used to calculate the pressure loss in the engine, fluid velocities, and the fluid temperature along the solar thermal absorber up to the nozzle. Using this information one can determine the performance of the engine. A sensitivity study was performed to investigate the effects of changes to several of the parameters that influence the engine's performance: propellant flow rate, convection coefficient, and absorber optical properties.

\section{Previous Work}

Using solar energy in a propulsion system was first proposed by Kraft Eriche in 1956[4]. No other work was done in this field until the early 1960's. During this time the Air Force's Rocket Propulsion Lab through a contract with Electro-Optical Systems, Inc. performed detailed analyses of the solar thermal rocket concept and carried out subscaled demonstrations of solar heating of the propellant. A Solar Hydrogen Rocket was developed. A five foot reflector focused solar energy onto a coil through which hydrogen flowed. The solar absorbers were made of 
molybdenum and henium. Hydrogen temperatures were measured up to about $4,400^{\circ} \mathrm{F}$ which corresponded to a calculated $\mathrm{I}_{\mathrm{sp}}$ of about $700 \mathrm{sec}$.

Several absorber/thruster concepts have been examined. Some of the designs have windows which allow the solar energy into the engine. In these designs refractory seedant material is used to absorb the energy and transfer heat to the working fluid. The seedant material and the fluid would be expelled from the engine's nozzle. A windowless concept has the solar energy being absorbed by the interior walls of the absorber/thruster and the heat is collected when the working fluid flows over the surface of the absorber. Though the windowed designs may be capable of higher temperatures, the windowless design is much simpler and was found to meet performance requirements[4].

\section{THE SOLAR THERMAL ENGINE DESIGN}

The solar thermal engine is shown in Figure 1. The absorber cavity was made of tungsten which has a melting point of $5,684^{\circ} \mathrm{F}$. The absorber wall was approximately 0.08 in. thick. The absorber cavity, which totaled 16.3 inches in length, was a cylinder with a hemispherical end. The diameter at the mouth of the absorber was 2.652 in. while the diameter at the end of the cylinder was 2.588 in. The cylindrical portion of the absorber was 15 in. long with the balance being the end cap. The tapering of the cylinder was to aid in the removal of the absorber from the mandrel on which it was sprayed using Vacuum Plasma Spray (VPS) techniques. The $\mathrm{H}_{2}$ ducts were formed using VPS techniques also. Tungsten was deposited on a mandrel that was threaded such that it produced a helical duct when the mandrel was removed. There were two parallel ducts each having a helical pitch of 1 , meaning that one helical revolution of the absorber was completed for every inch of the absorber length. The shell that formed the ducts had an outer diameter of 3.213 in. at the beginning and a diameter of 3.170 in. at the end. The ducts were triangular in cross section with an area of $0.045 \mathrm{in}^{2}$., base of $0.45 \mathrm{in}$. and 
height of $0.21 \mathrm{in}$. The walls of the ducts were $0.08 \mathrm{in}$. thick. There was a gap of $0.204 \mathrm{in}$. between tip of the duct walls and the insulation. The insulation was Fiberform ${ }^{D}$ a high temperature insulation that was designed to operate at temperatures up to $5000^{\circ} \mathrm{F}$. The Fiberform ${ }^{\oplus}$ insulation facing the ducts had a low emittance graphite coating, providing a reflective coating effective at high temperature operation. The collar at the mouth of the absorber was made of nickel. The entire engine and insulation assembly is enclosed in stainless steel.

The energy used to heat the engine is provided through concentrated solar energy. The solar energy spectral distribution is approximately 7 percent ultraviolet, $46 \%$ visible and $47 \%$ near infrared. The majority of the energy emitted by the sun is at a much shorter wave length than the infrared energy emitted by a body near the design temperature of the surface of the absorber. This allows for the selection of finishes that are absorbing or reflective in the solar spectrum while performing oppositely at long infrared wavelengths. A desire for an engine of this type would be to have a high solar absorbtivity and a low emissivity at the temperature of the surface, because that would enable more energy to be transferred to the fluid rather than be radiated to the environment. The absorbitivity $(\alpha)$ is the fraction of energy that is absorbed by a surface compared to a the energy absorbed by black surface $(\alpha=1)$, while the emissivity is the fraction that is emitted due to the temperature of the surface compared to a black $(\epsilon=1)$ surface of the same temperature. The design specification of the engine required that the surface of the first 4 inches of the absorber cavity be polished to have an absorbtivity $(\alpha)$ of 0.25 while the balance of the absorber would have an absorbtivity of 0.75 at solar radiation wavelengths. The absorbtivity of the first 4 inches of the absorber was reduced to help increase the reflectance in that area. 


\section{THERMAL MODEL OF ENGINE}

A thermal model was developed to represent the conditions in which the engine would be tested. The engine would be tested in a vacuum chamber, thus it was assumed that the heat transfer from the outer surface of the engine would be due only to radiation. Also the solar flux input is based on what is expected to be produced in the test environment. No attempt was made to model the nozzle flow or heat transfer in the nozzle area. Only the heat transfer and fluid dynamics associated with the absorber, ducts and the insulation were modeled. A detailed description of the model and the results of the analysis are given in reference 5 .

\section{Engine Model Description}

The solar thermal engine was modeled using SINDA (Systems Improved Numerical Differencing Analyzer)[6]. The SINDA model was a set of nodes which were used to discretize the different components of the engine. A network of nodes simulating all parts of the engine was connected using conductors: radiation, convection, and conduction. SINDA uses finite difference techniques to solve the network for nodal temperatures.

Radiation view factors were calculated using TRASYS (Thermal Radiation Analysis System) [7] which is a program that has the general capability to solve the radiation aspects of a thermal analysis problem. It can be used to calculate the internode radiation interchange of a model as well as calculate the incident and absorbed heat rate data from environmental heat sources. For this analysis it was used to solve the complex radiation interchange between all of the nodes in the absorber and the environment. TRASYS was also used to calculate the radiation exchange between the flow channel walls and the insulation.

Figure 2 is a schematic of the absorber nodes as they would appear if the cylinder has been sliced down one side and unrolled. The absorber cavity was divided into 15 rings which were 1 in. in width. The rings were then each divided circumferentially into 12 equal segments. This formed 180 nodes that made up the cylinder of the absorber cavity. The endcap was a single 
node that was a 1.3 in radius hemisphere. Figure 3 shows the $\mathrm{H}_{2}$ flow paths over the absorber elements. There were two separate parallel flow paths.

\section{Fluid Flow Model}

Of particular interest in modeling the engine was the temperature of the fluid as it flowed along and exited the absorber. The primary mode of heat transfer to the fluid was forced convection, so part of the fluids modeling focused on determining the convection coefficients needed to calculate the temperature of the fluid. One-hundred and eighty fluid nodes per duct were used to simulate the $\mathrm{H}_{2}$ flowing through the engine. Single phase (gas) fluid flow was assumed since this is the fluid condition that is expected during testing of the engine. The pressure loss of the fluid as it flowed through the engine ducts was also of interest.

Both of these were complicated by the shape of the duct and also curvature effects due to the coiled configuration of the ducts. As described in detail in reference 5 , these effects were taken into account in the model, and the curvature had a significant effect on the value of the convection coefficient in the ducts.

\section{Distribution of Incident Light Flux}

The total spectrum has to be considered when examining the radiation environment for the solar thermal engine: the visible for solar energy input and the infrared for radiation of absorbed energy. Since the heat input to the absorber is solar energy (visible light) the optical properties for the calculations were values that were integrated over the solar spectrum, for the tungsten surface. QFLUX, a Monte Carlo simulation tool, was used to determine the light distribution inside the absorber cavity used for the solar energy input for the analysis. The code divided the cavity into small nodes then generated random light rays entering the cavity. The light flux distribution inside the cavity was calculated by determining where each of the rays struck the surface of the absorber and where its reflections struck. The code calculated how much of the 
energy was absorbed based on the solar absorbtivity of the surface, and the balance of the energy was reflected. The light ray was continually reflected until its intensity was only $1 \%$ of the original value

The output from the simulation was a normalized distribution of the light on the absorber specific to the optical properties of the absorber and the angle at which it was concentrated. In this case the light had been concentrated such that it had a half angle of $32^{\circ}$ as it entered the absorber cavity. The flux data was given in terms of $R$, where $R$ is the amount of energy deposited on a single absorber element in the simulation and is defined by

$$
R=\frac{\frac{q_{x y}}{a_{x y}}}{\frac{Q_{T}}{A_{\text {mouth }}}}
$$

where $q_{x y}$ is the light flux over the area $a_{x y}$ and $Q_{r}$ is the total energy passing through the area of the mouth $A_{\text {mounh }}$ of the absorber.

The light distribution profile is shown in Figure 4. The nominal design was specified to have solar wavelength absorbtivity of 0.25 for the initial 4 (polished) inches of the absorber and 0.75 for the remainder, with corresponding infrared wavelength emissivities of 0.1 and 0.22 . The distribution has two peaks at about 2.5 in. and 5 in. along the absorber cylinder. The first peak is due to the light entering the absorber at a half cone angle of $32^{\circ}$ and striking the surface and being absorbed. The second peak is caused by the reflections of light from the first region of incidence. Light is reflected further into the absorber, but it is more evenly distributed on the absorber surface. The peak at the end of the absorber is due to light directly incident on the surface from the source

\section{RESULTS}

The cases analyzed were based on tests planned to be performed at the Air Force Research Laboratory (AFRL) test facility. Ten kilowatts of energy was specified to be 
concentrated into the absorber cavity of the engine, with gaseous $\mathrm{H}_{2}$ flowing through the absorber at the rate of $2 \mathrm{lb} / \mathrm{hr}$ for the nominal design. The engine was assumed to be in a vacuum chamber and at an initial temperature of $70^{\circ} \mathrm{F}$. (For all cases analyzed, the results showed that the flow was laminar, the Mach number was less than 0.1 , and the pressure drop from the duct inlet to the chamber was 5 psi or less.)

Shown in Figure 5 are steady state results for the fluid temperature distribution along the length of the absorber, with the fluid chamber temperature reaching about $3850^{\circ} \mathrm{F}$. The transient fluid temperature distribution is shown in Figure 6, where it is seen that after 30 minutes of Operation the fluid chamber temperature is within about $40^{\circ} \mathrm{F}$ of the steady state temperature and that even after only 5 minutes of operation the temperature is within $500^{\circ} \mathrm{F}$ of steady state. Steady state axial distributions of temperatures at different radii at the $0^{\circ}$ circumferential location are presented in Figure 7, and the dominating role of the heat transfer resistance of the insulation layer is quite evident. Results of a study in which the insulation thickness of the nominal design was varied are shown for axial termperature distributions in Figure 8 and for the fluid chamber temperature in Figure 9. Considering the fluid chamber temperature, it appears relatively little is gained by increasing the insulation thickness above about one inch.

Additional cases were run to investigate the sensitivity of the results from the model to several of the input variables. It was found that increasing or decreasing the convection coefficient in the ducts by $50 \%$ had a negligible effect on the temperature of the fluid at the chamber.

Cases were also run in which the emissivity of the absorber surface was increased or decreased by $50 \%$. The results of the radiation heat transfer sensitivity analysis show that with lower emissivity values the temperature of the $\mathrm{H}_{2}$ increases. Less heat was radiated to the boundary through the mouth of the absorber which means that the fluid received more heat and experienced increased temperatures. 
Table 5.1 shows that when emissivity was reduced by $50 \%$ the amount of heat that was radiated through the mouth of the absorber was $2640 \mathrm{BTU} / \mathrm{hr}$., and the fluid exit temperature was $3904^{\circ} \mathrm{F}$. In the nominal case the radiated heat was $3104 \mathrm{BTU} / \mathrm{hr}$. and the fluid temperature was $3847^{\circ} \mathrm{F}$. And finally, in the case where emissivity was increased by $50 \%$ the radiated heat was $3411 \mathrm{BTU} / \mathrm{hr}$., and the exit temperature was $3809^{\circ} \mathrm{F}$. Table 5.2 shows the relative amount of heat that was radiated by the absorber as the emissivity of the absorber was changed. Nine percent of the total heat $(10 \mathrm{~kW})$ was radiated for the nominal case whereas only $7.7 \%$ was radiated for the $50 \%$ reduced case, while $10 \%$ was radiated for the $50 \%$ increased case. This table also shows the amount of heat that was radiated to the environment from the outer shell of the engine. The engine performance is thus relatively insensitive to $\epsilon$. Multiplying $\epsilon$ by a factor of 3 only changed the chamber temperature from $3900^{\circ} \mathrm{F}$ to $3800^{\circ} \mathrm{F}$.

The performance of the engine is very sensitive to the hydrogen flow rate, as shown in Figure 10. Decreasing the flow rate from 2 to $1 \mathrm{lb} / \mathrm{hr}$ increased the chamber temperature to about $4700^{\circ} \mathrm{F}$. Of course, the reduced mass flow rate also would reduce the thrust, thus making the engine's performance less attractive.

\section{SUMMARY AND CONCLUSIONS}

A direct gain solar thermal engine has been analyzed and the results presented. Shown was that the STUS engine design, with input energy of $10 \mathrm{~kW}$, will have a chamber temperature of $3850^{\circ} \mathrm{F}$ (which corresponds to an $I_{s p}$ of about 820 seconds. The $\Delta p$ through the engine was calculated to be about 4.9 psi.

Sensitivity analyses show that the major factor that affects the temperature of the fluid is the mass flow rate of the working fluid if the collected solar energy is held constant. Reducing the hydrogen mass flow rate to $1 \mathrm{lb} / \mathrm{hr}$. increases the chamber temperature to about $4700^{\circ} \mathrm{F}$. Though 
mass flow rate appears to offer the most opportunity to affect the temperature of the fluid, the potential to adversely affect the thrust of the engine may not make this option viable.

The temperature of the fluid is sensitive to the convection coefficient $(h)$, but not to a large extent. For $h$ to have a major effect on the temperature, the convection coefficient would have to be changed by a factor greater than 2 . This implies that a simple geometry change of the duct is not enough to increase the fluid temperature. Similarly the emissivity of the absorber surface must be much lower to increase the chamber temperature of the fluid. Also implied in these sensitivity analysis results is that the uncertainty in the emissivity and the fluid properties used to calculate $h$ has a minimal effect on the results.

When developing a flight engine the mass and volume occupied are also very important. Reducing the insulation thickness of the engine reduces the mass and volume but also reduces the engine's chamber temperature while increasing the outside shell temperature. Results of the insulation sensitivity analysis show that with insulation approximately 0.6 in. thick the steadystate chamber temperature will be approximately $3740^{\circ} \mathrm{F}$ while the stainless steel outside shell temperature will be about $1000^{\circ} \mathrm{F}$. This chamber temperature is only $100^{\circ} \mathrm{F}$ less than the chamber temperature of the engine with 3.2 in. of insulation.

\section{References}

[1] Solar Thermal Upper Stage (STUS), MSFC In-House Feasibility Study, Vol. 1, August 1994.

[2] Strumpf, Hal J., Borghese, Joseph B., and Keating, Ronald F.," Conical Solar Absorber/Thruster for Space Propulsion", Solar Engineering Vol. 2, ASME 1995.

[3] Gerrish, Harold, "Solar Thermal Propulsion Evaluation", CDDF 95-13, NASA Marshall Space Flight Center, November 1995.

[4] Selph, C. C., "The Place of Solar Thermal Rockets in Space", APL 1981 JANNAF Propulsion Meeting, Vol. 2, pp. 265-288.

[5] Alexander, R. A., "Thermal/Fluids Analysis of a Direct Gain Solar Thermal Upper Stage Engine," M.S. thesis, University of Alabama in Huntsville, 1998.

[6] Network Analysis Associates, Inc., SNDA/G User's Guide, First Edition, 1994.

[7] Lockheed Engineering and Management Services Company, Thermal Radiation Analyzer System (TRASYS) User's Manual, April 1988. 
Table 5.1 Heat Transfer Results from Radiation Sensitivity Analysis

\begin{tabular}{|c|c|c|c|c|}
\hline $\begin{array}{c}\text { Factor Applied } \\
\text { to } \epsilon\end{array}$ & $\begin{array}{c}\text { Heat Reradiated } \\
\text { Through } \\
\text { Absorber Mouth } \\
\text { (BTU/hr.) }\end{array}$ & $\begin{array}{c}\text { Heat Radiated } \\
\text { from Outer Shell } \\
\text { (BTU/hr.) }\end{array}$ & Total (BTU/hr.) & $\begin{array}{c}\text { Chamber } \\
\text { Temperature } \\
\text { (FF) }\end{array}$ \\
\hline 0.5 & 2641 & 1218 & 3859 & 3904 \\
\hline 1.0 & 3104 & 1311 & 4414 & 3847 \\
\hline 1.5 & 3411 & 1373 & 4784 & 3806 \\
\hline
\end{tabular}

Table 5.2 Absorber Heat Balance

\begin{tabular}{|c|c|c|c|c|}
\hline $\begin{array}{c}\text { Factor Applied } \\
\text { to } \epsilon\end{array}$ & $\begin{array}{c}\text { Heat Reradiated } \\
\text { Through } \\
\text { Absorber Mouth } \\
(\%)\end{array}$ & $\begin{array}{c}\text { Heat Radiated } \\
\text { from Outer Shell } \\
(\%)\end{array}$ & Total (\%) & $\begin{array}{c}\text { Heat into the } \\
\text { Fluid (\%) }\end{array}$ \\
\hline 0.5 & 7.7 & 3.6 & 11.3 & 88.7 \\
\hline 1.0 & 9.1 & 3.8 & 12.9 & 87.1 \\
\hline 1.5 & 10.0 & 4.0 & 14.0 & 86.0 \\
\hline
\end{tabular}




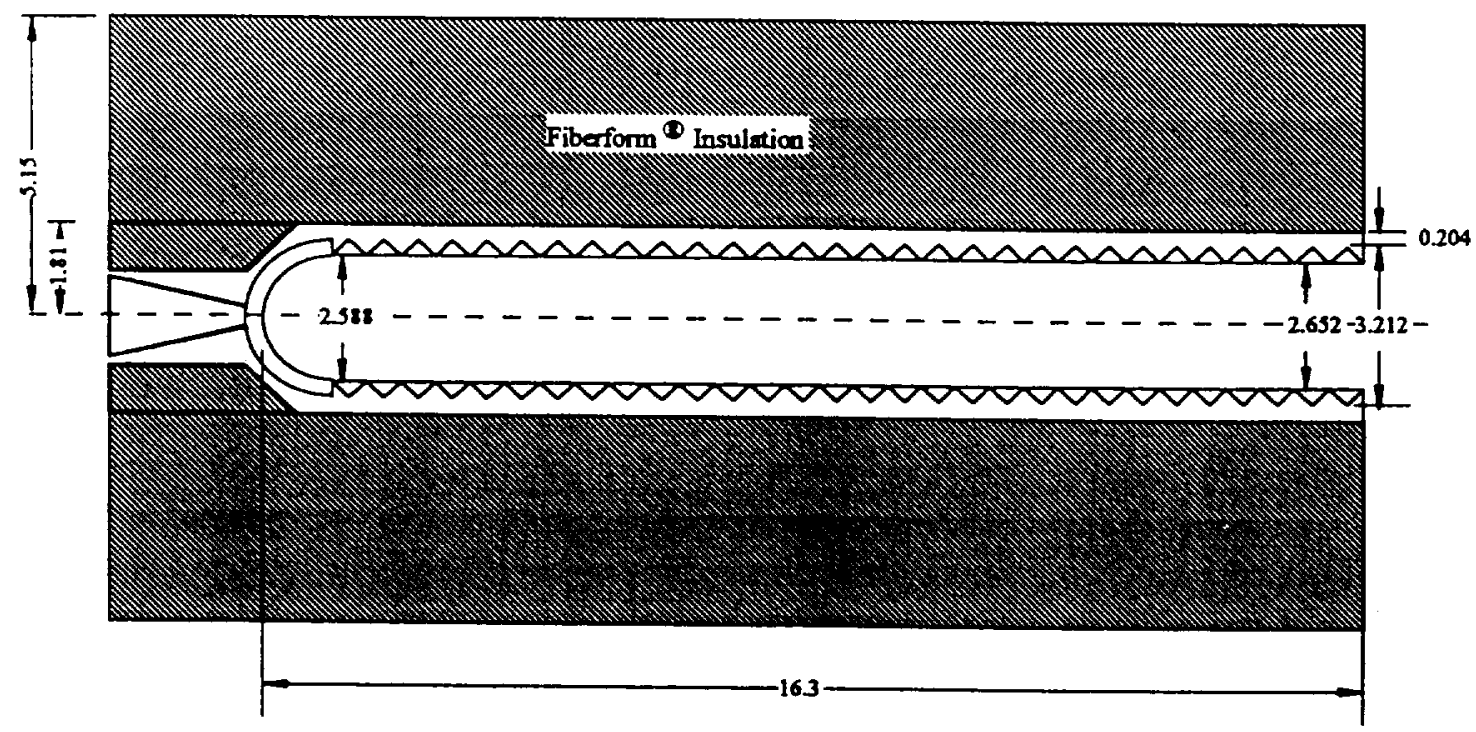

All Dimperasions in lecter

Figure 1. Schematic of Solar Thermal Engine 


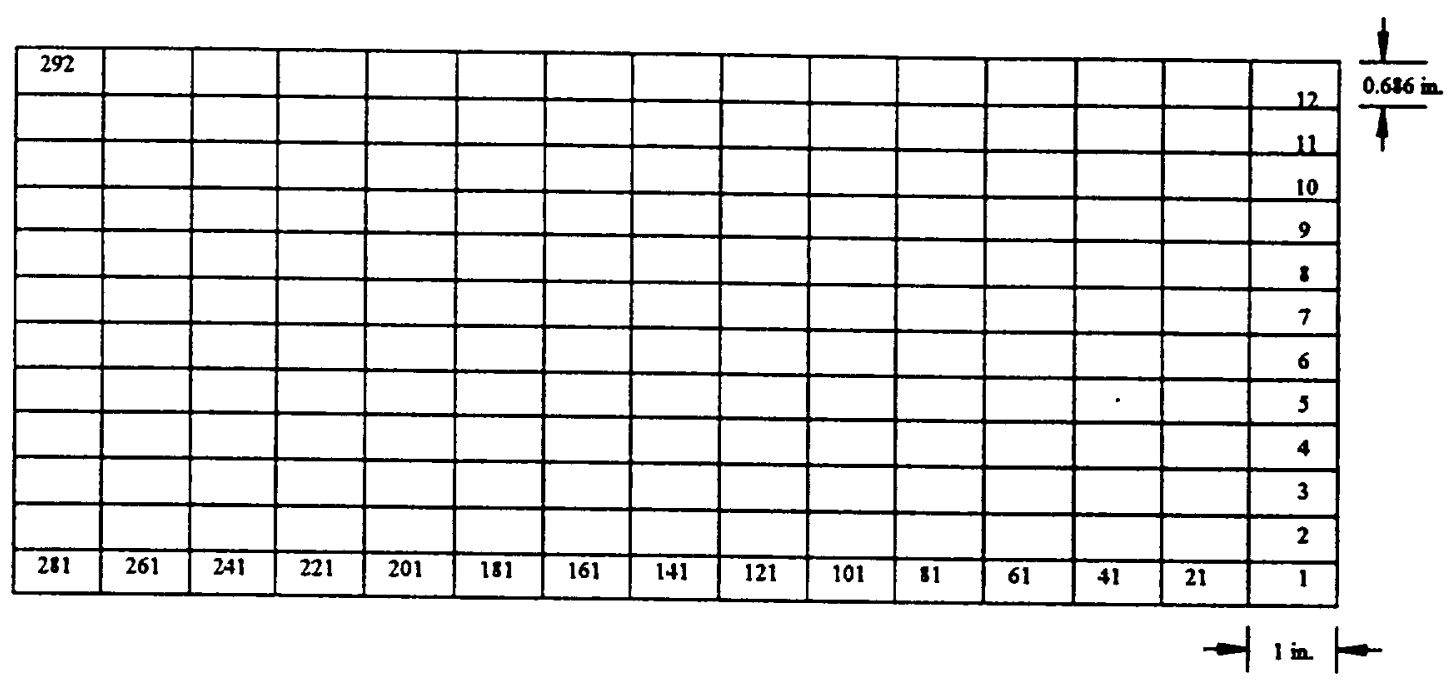

Figure 2. Nodal layout of the absorber cylinder.

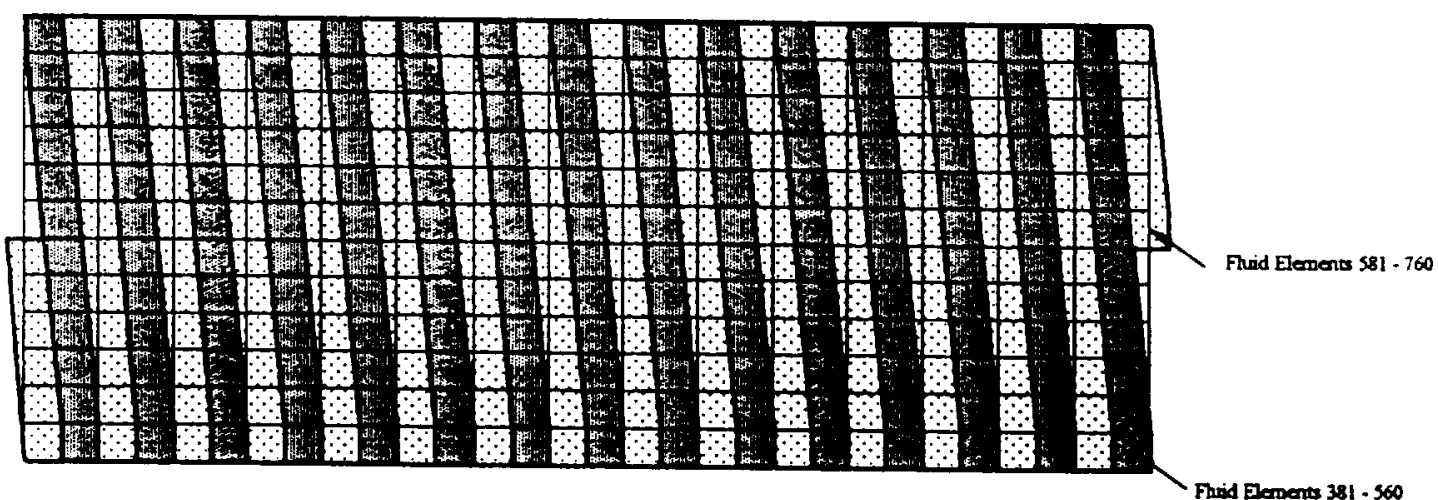

Figure 3. Fluid flow paths over absorber nodes. 


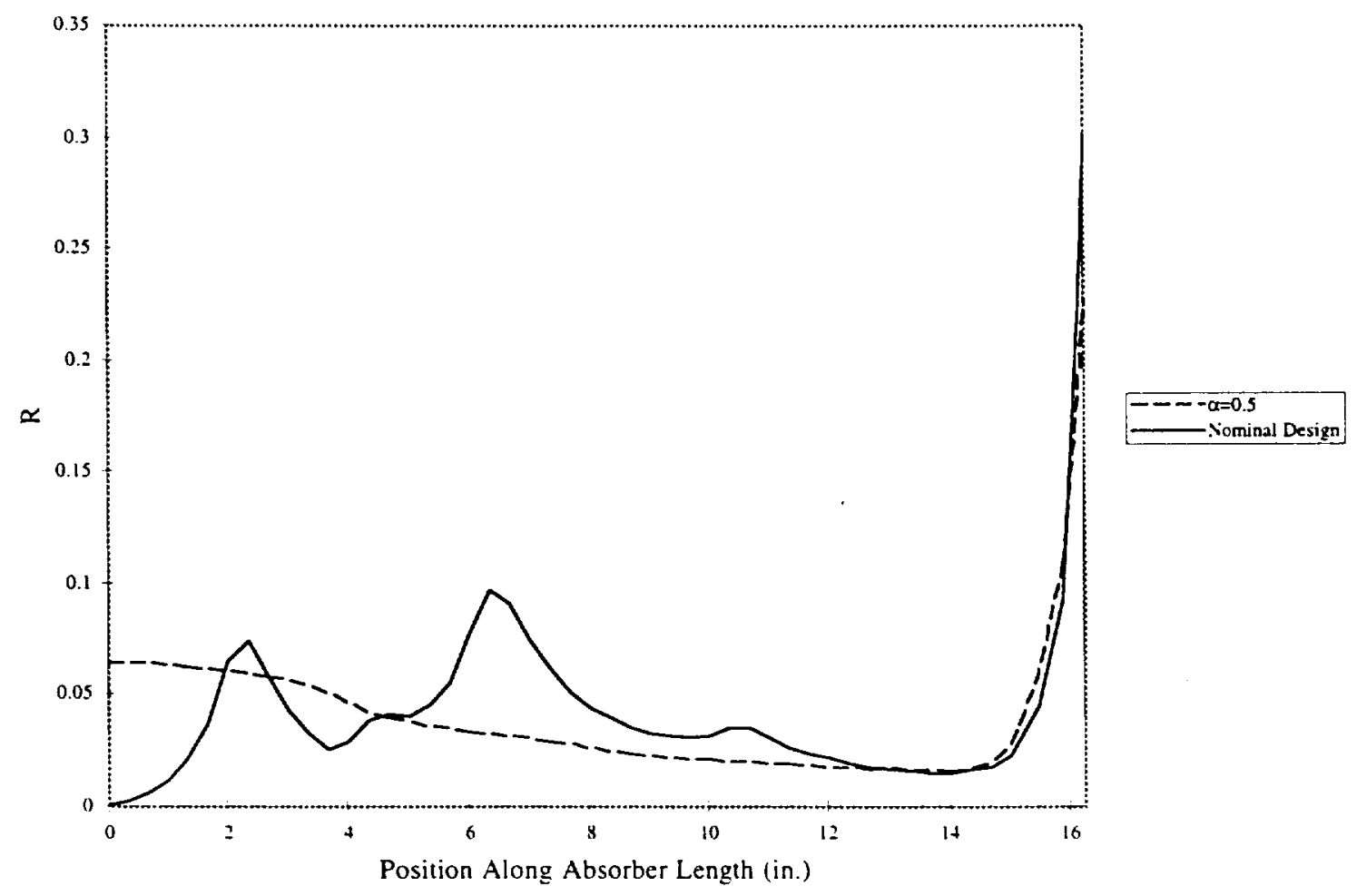

Figure 4. Incident Light Flux Distribution

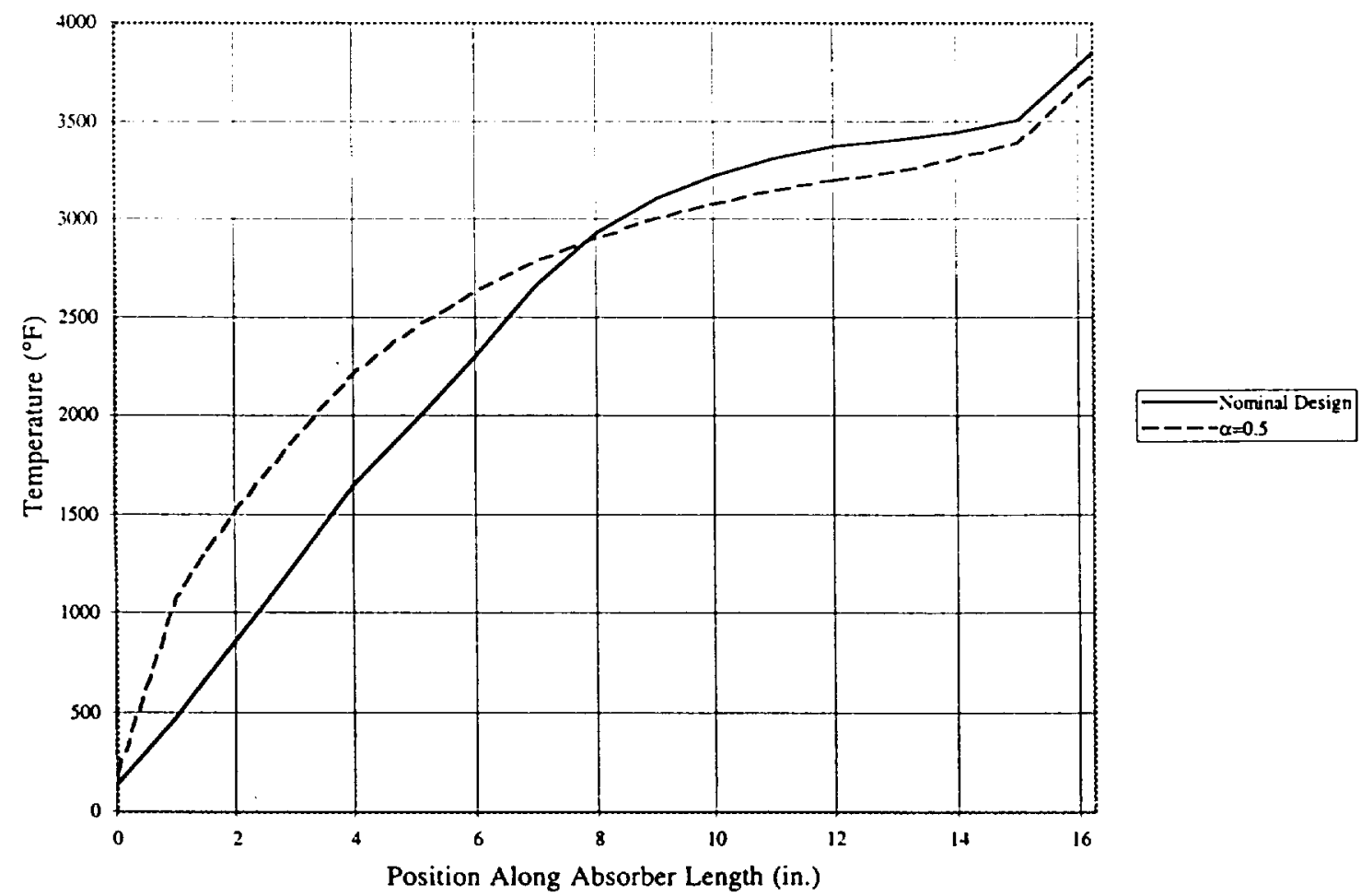

Figure 5. Fluid temperature along Absorber Length 


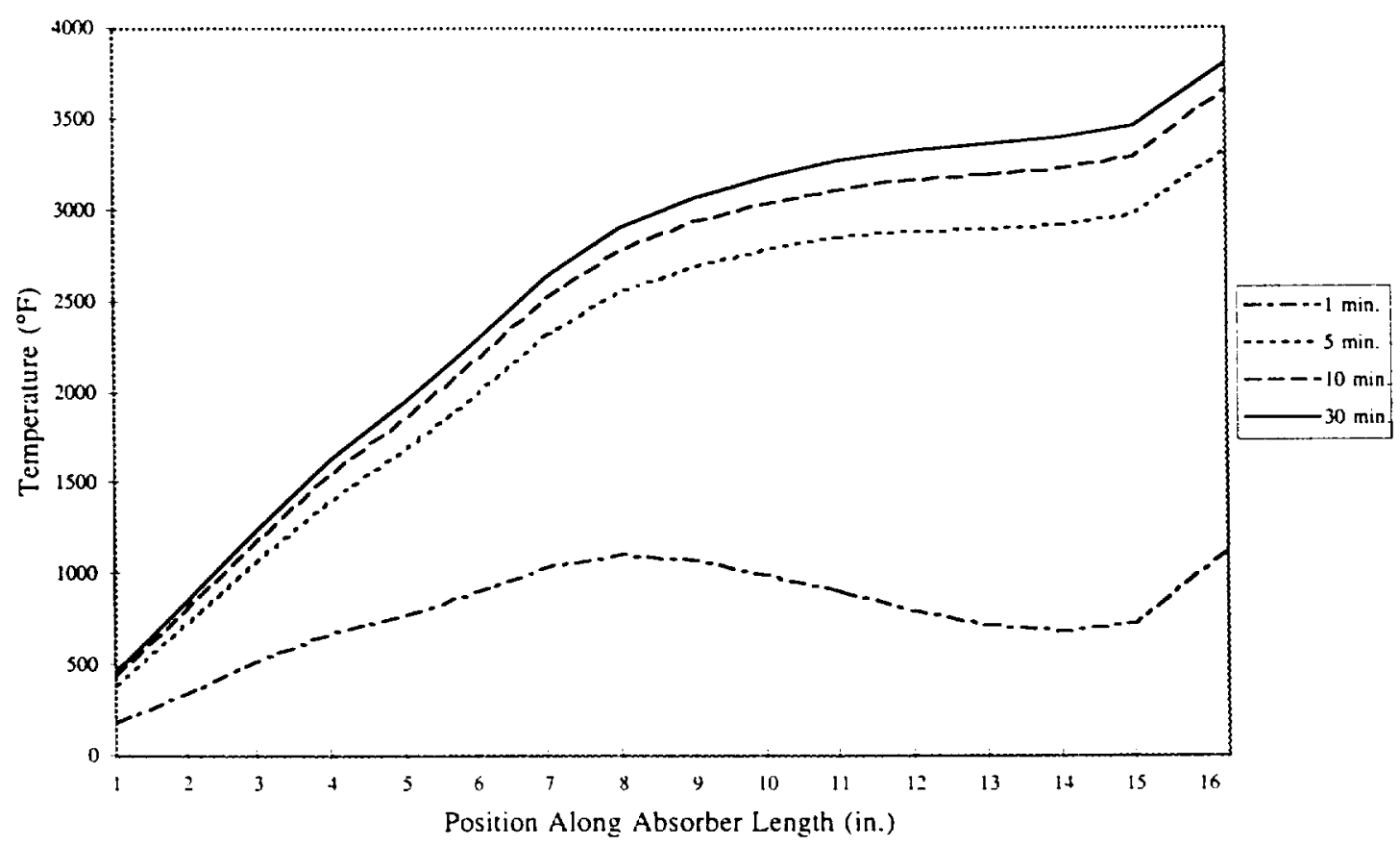

Figure 6. Axial Distributions of Temperature-Transient Results

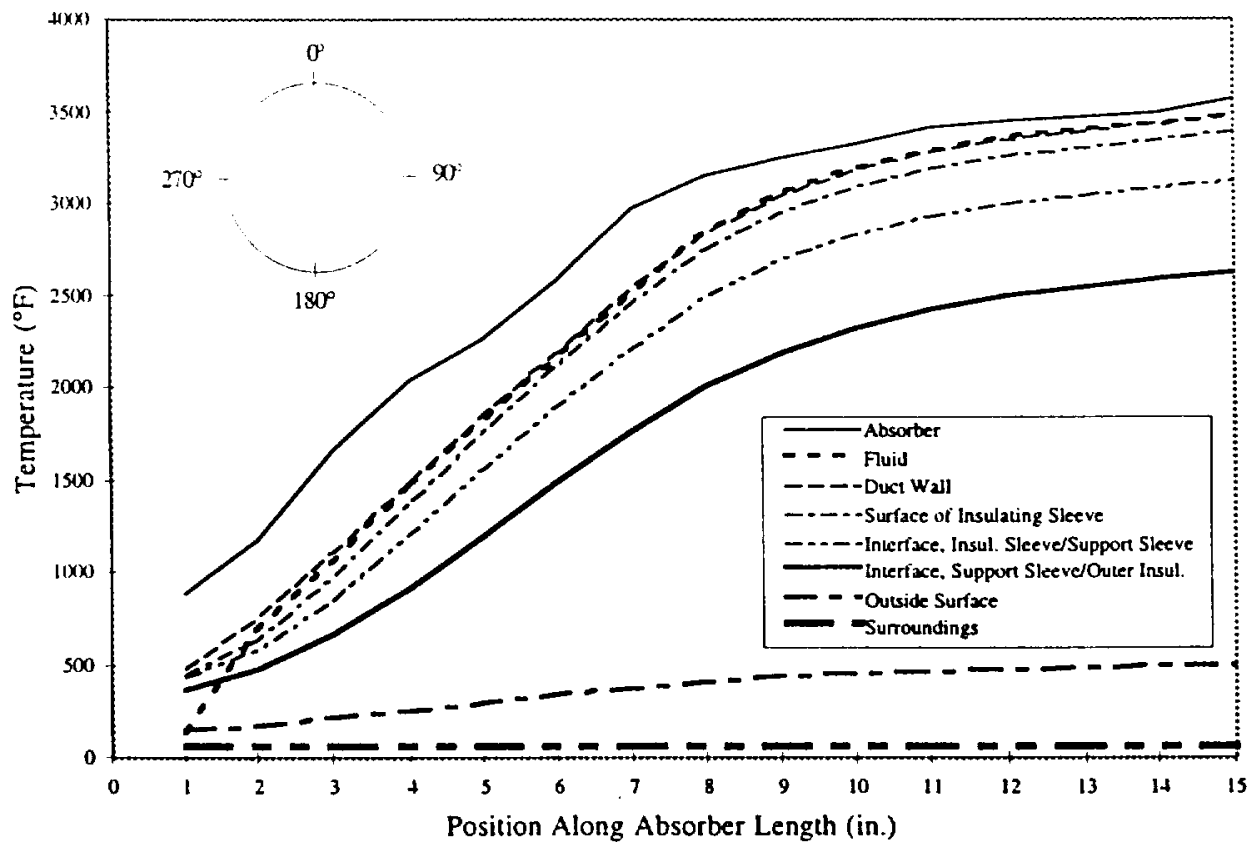

Figure 7. Axial Distributions of Temperature at Different Radii 


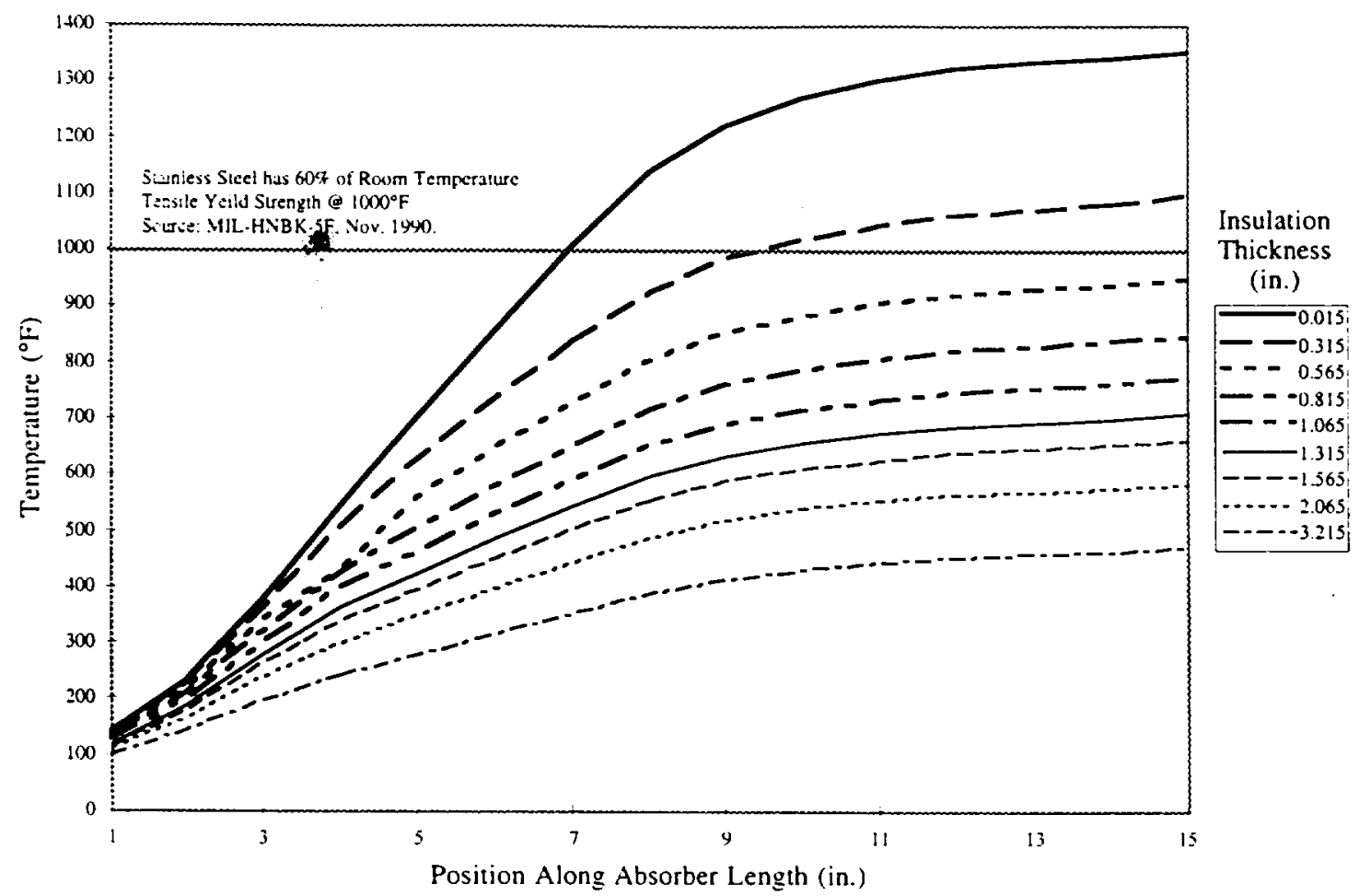

Figure 8. Axial Temperature Distribution of Outer Shell as a Function of Insulation Thickness

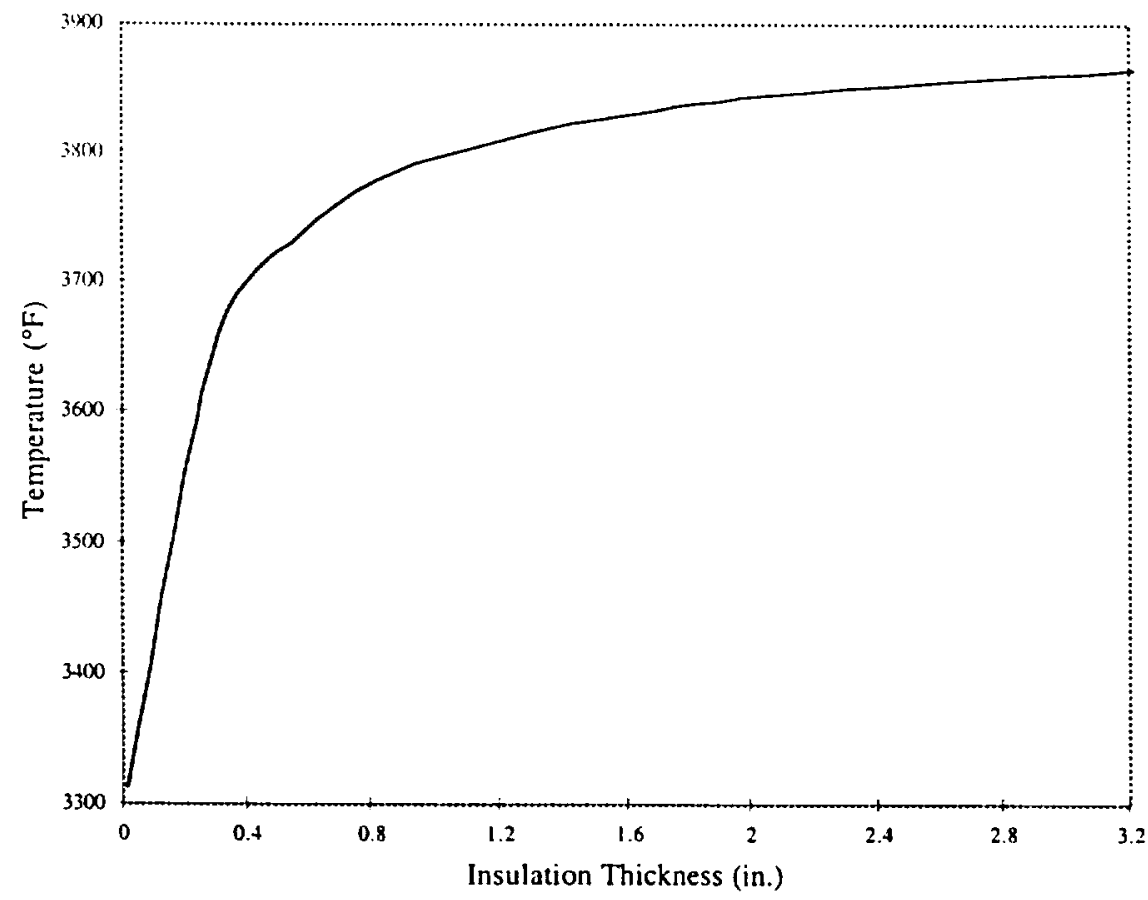

Figure 9. Fluid Chamber Temperature as a Function of Insulation Thickness 


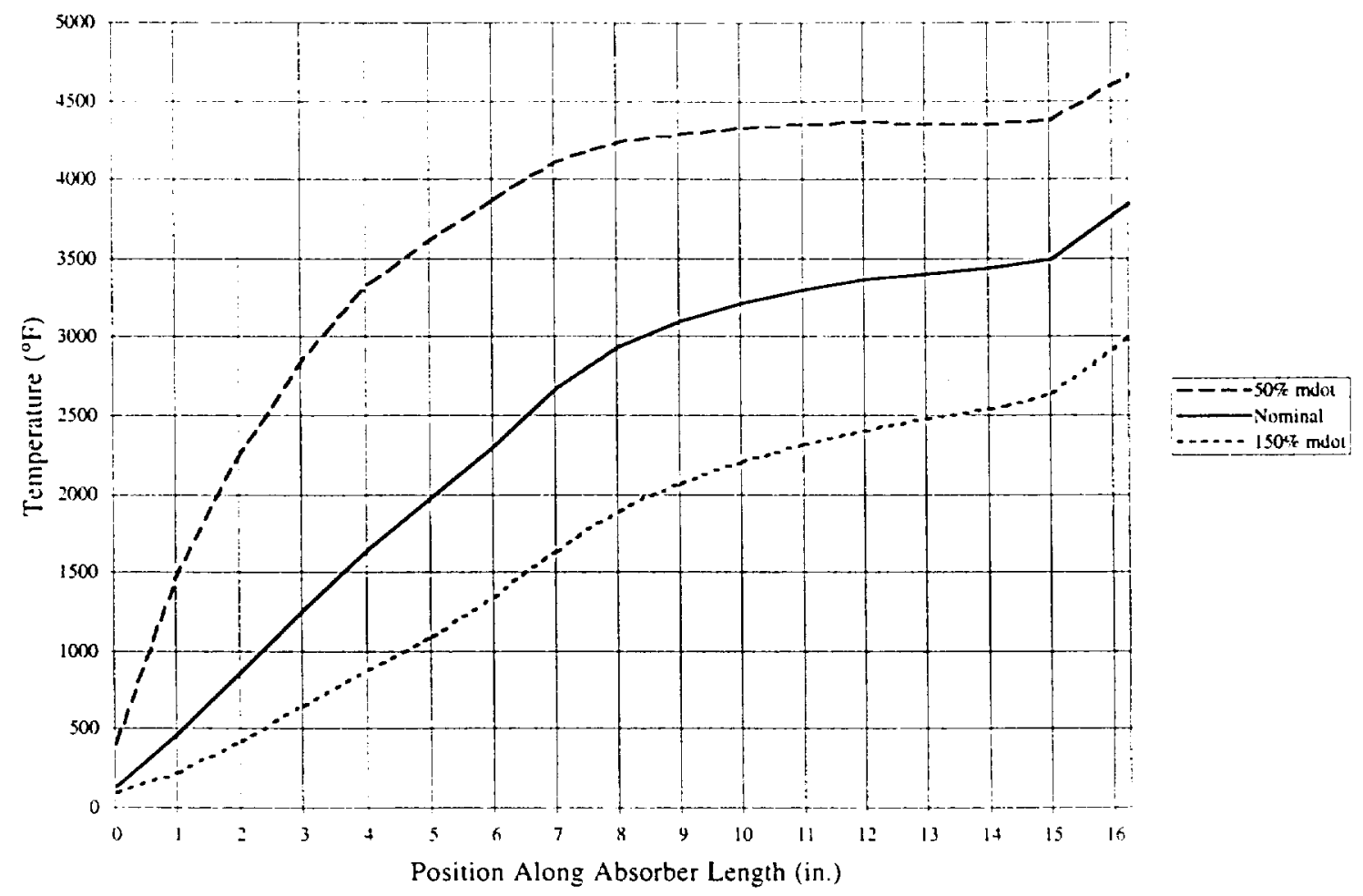

Figure 10. Influence of Hydrogen Flow Rate on Fluid Temperature. 